In a previous publication ${ }^{1}$ attention was directed to the failure to germinate resting spores of Peronospora Schleideni in the laboratory, even when subjected to different treatments. The peculiar germination of one untreated spore, kept in a sealed moist chamber for several months, was mentioned in the same paper. Since then, the germination of a number of resting spores of this fungus has been seen under more natural conditions.

In the year 1930, I found a crop of onions in which enormous numbers of resting spores of onion mildew were being produced in the foliage. A sack-full of these leaves was collected and taken home, being then trampled into a large box provided with holes at the bottom for drainage. Bacterial action soon commenced and the leaves went down into a vilesmelling mess, which after the lapse of a few weeks dried up, leaving a fine material a couple of inches deep in the box consisting of decayed leaf tissue and abundance of resting spores. The box has remained fully exposed in a garden since then, and periodically, a little of the fine material has been removed in order to photograph any change occurring in the spores, and also to test for germination. The collapsed oogonium is remarkably persistent, and forms an additional protective layer $2-3 \mu$ in thickness around the thick spore wall.

Little or no change was seen in the spores until they were three years old, when it was found that in some cases the oogonium had disappeared wholly or in part, and the spore wall had thinned down to $2-1 \mu$. Germination of an odd spore was obtained at the end of four years, and after a further five months, on placing some of the material from the box in water in a warm room, approximately 1 per cent of the spores germinated after eleven days, a total of twenty-seven being observed. Germination in all cases was by a stout germ-tube $6-9 \mu$ in diameter, which was capable of considerable growth in water, up to $960 \mu$. In a number of cases this germ-tube branched. Spores which were partly free from the oogonium and germinated were of a light straw colour; in some instances the germ-tube pushed its way out through the enveloping folds of the persistent oogonium. Whilst thinning of the spore wall has taken place in quite a considerable number of the spores, others show no visible change from those photographed at the end of the first year, and judging from their appearance they are probably good for another five years.

So far as I am aware, the above is the only record of the germination of resting spores of onion mildew.

$$
\begin{aligned}
& 20 \text { Wigan Road, } \\
& \text { Drumcondra, }
\end{aligned}
$$

Dublin.

Jan. 15.

${ }^{1}$ Murphy, Paul A,, and McKay, Robert, J. Dept. Lands and Agric. Dublin, 31, 69-76; 1932.

\section{Crystallisation of Human Serum Albumin}

Apart from Oswald's report ${ }^{1}$ that he had obtained globuliths from the albumin fraction of human ascitic fluid, we have been unable to find any account of the crystallisation of human serum albumin. Recently we have succeeded in obtaining albumin crystals from two separate batches of pooled human sera.

Serum was separated from the clot, heated for 25 minutes at $56^{\circ} \mathrm{C}$. and fractionated within two or three days of bleeding. After addition of an equal volume of saturated ammonium sulphate and removal of the globulin, crystallisation was brought about by adding normal acetic acid. The requisite amount was first determined for 5 c.c. portions, acid being added from a micro-burette until the first faint permanent turbidity was observed; about $0 \cdot 21$ c.c. were required. Whereas crystals of horse serum albumin usually appear within two hours of acidification under these conditions, we were unable to detect crystals in our preparations of human albumin before the following day. Our experience has indicated that crystallisation of human albumin takes place within narrower limits of hydrogen ion concentration than is the case with horse serum albumin.

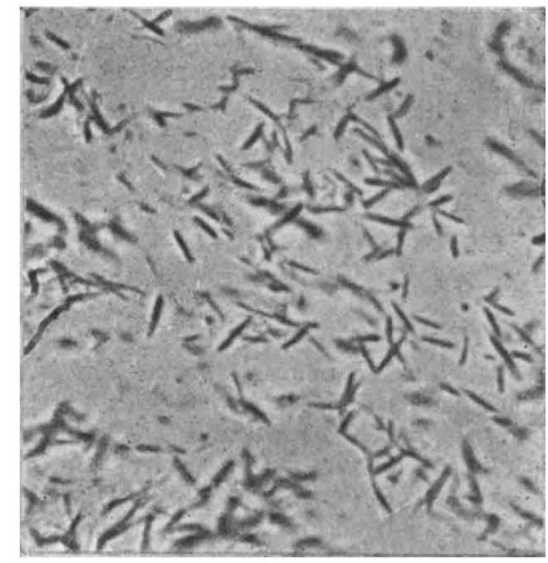

FIa. 1. Crystals of human serum albumin. $\times 540$.

The main bulk of the protein solution was treated by adding slowly the calculated amount of acetic acid. After well-defined crystals had formed, the yield was increased by addition of a further amount of acid-half the volume of that first used. Two or three hours later a third addition of acid, equal to the second quantity, was made. The following day the crystals were collected by filtration.

The crystals obtained were readily visible under the $1 / 6$ power of the microscope as small fine needles (Fig. 1). As in the case of horse serum albumin, the crystals dissolved in water to give an opalescent solution which was clarified by filtration, the turbidity being apparently due to lipid associated with the protein.

$5 \mathrm{gm}$. of crystalline albumin was obtained from 300 c.c. of serum, representing a yield of about 40 per cent of its albumin content. Recrystallisation can be brought about by the method described by Adair and Robinson ${ }^{2}$. MURIEL E. AdaIR.

$$
\begin{aligned}
& \text { Department of Pathology, } \\
& \text { Cambridge. } \\
& \text { Jan. 8. } \\
& \text { 2 Z. physiol. Chem., 95, 102; } 1915 . \\
& \text { Biochem. J., 24,993; } 1930 .
\end{aligned}
$$

\section{Stability of the Acetyl Radical}

IT is usually supposed that free acyl radicals do not survive the shock of thermal or photo-dissociation of the molecule from which they might be formed or, if formed, decompose further before they can react with other molecules to give rise to isolable products. Thus Rice has shown that no diacetyl results from the thermal decomposition of acetaldehyde ${ }^{1}$, and Norrish has concluded as a result of his studies of 